\title{
Taxonomic and functional diversity of microbial community from a mining environment
}

\author{
Julliane D Medeiros ${ }^{1}$, Laura R Leite ${ }^{1}$, Sara Cuadros-Orellana ${ }^{2}$, Guilherme Oliveira $2^{2^{*}}$ \\ From Latin American Student Council Symposium 2014 (LA-SCS 2014) \\ Belo Horizonte, Brazil. 27 October 2014
}

\begin{abstract}
Background
Biomining uses acidophilic and chemolithotrophic microbes capable of oxidizing iron and sulfur to recover metals of interest from complex minerals. One of the most critical issues in mining environments is the generation of acid mine drainage (AMD) that pollutes water and sediments with acids and metals. The Sulfate-reducing bacteria (SBR) are an alternative to bioremediate contamination of AMD. The current knowledge on the microbial diversity and the metabolic pathways involved in bioming and bioremediation is still limited. In this context, metagenomics has become a valuable tool to investigate previously uncultured microorganisms in environmental samples. The aim of this study was to assess the taxonomic and functional microbial diversity in a mining area in the Brazilian Amazon.
\end{abstract}

\section{Results}

We collected acid mining drainage water; sediment and water from the surface and 15 meters depth of a tailings dam that received $\sim 90$ million tons of chalcopyrite mining waste. The prokaryotic biomass from water samples was concentrated on filters with $0.22 \mathrm{~m}$ pores. Metagenomic DNA was isolated and the V4 region of the 16S rRNA was amplified. Shotgun and amplicon libraries were sequenced on Ion Torrent platform. We used Qiime to cluster the sequences into OTU and we observed that the microbial diversity was higher on the sedi- ments and AMD metagenomes (Sediment - Chao:1988; Shannon:6.05 / AMD Chao:2375; Shannon:5.03) compared to the water (Chao:370; Shannon:4.16). MG-RAST was used to classify the reads (representative hit, identity cut-off $>=75 \%$ ) Biomining uses acidophilic and chemolithotrophic microbes capable of oxidizing iron and sulfur to recover metals of

\footnotetext{
*Correspondence: oliveira@cebio.org

${ }^{2}$ CPqRR/Fiocruz, Minas Gerais, Brazil

Full list of author information is available at the end of the article
}

interest from complex minerals. We collected acid mining drainage water; sediment and water from the surface and 15 meters depth of a tailings dam that received $\sim 90$ million tons of chalcopyrite mining waste. The prokaryotic biomass from water samples was concentrated on filters with 0.22 $>=75 \%$ ), and the results indicate the dominant phyla on water metagenomes were Proteobacteria (49.3\%), Actinobacteria (31.6\%) and Bacteroidetes (7.6\%). The most abundant phyla in sediments were Proteobacteria (48.7\%) Bacteroidetes (17.2\%) and Firmicutes(7.5\%). We analyzed OTUs from specific SRB-families (Thermodesulfovibrionaceae, Desulfobacteraceae, Syntrophaceae, Peptococcaceae, Desulfuromonadaceae, Desulfomicrobiaceae) and there was an enrichment of these families in sediment and AMD samples. Blastx against NR was used for functionally classify reads in MEGAN using the SEED and KEGG hierarchy.

\section{Conclusions}

Despite the prevalence of housekeeping functions, we observed reads matching relevant adaptive traits, such as sulfur oxidation, $\mathrm{ABC}$ transporters and resistance to metal. Our data indicate the potential for biomining and biore- mediation on the studied environments, however new rounds of sequencing must be done for more conclusive results.

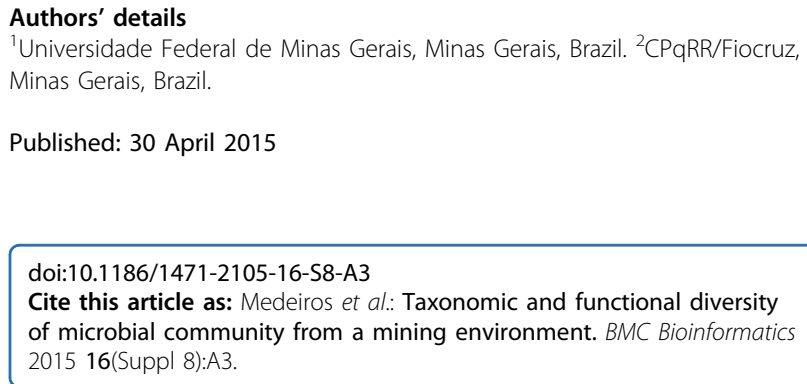

Published: 30 April 2015

doi:10.1186/1471-2105-16-S8-A3

Cite this article as: Medeiros et al:: Taxonomic and functional diversity of microbial community from a mining environment. BMC Bioinformatics 2015 16(Suppl 8):A3.

() Biomed Central

(c) 2015 Medeiros et al; licensee BioMed Central Ltd. This is an Open Access article distributed under the terms of the Creative Commons Attribution License (http://creativecommons.org/licenses/by/4.0), which permits unrestricted use, distribution, and reproduction in any medium, provided the original work is properly cited. The Creative Commons Public Domain Dedication waiver (http://creativecommons.org/publicdomain/zero/1.0/) applies to the data made available in this article, unless otherwise stated. 